\title{
The Design of high Power LED Chip Radiator
}

\author{
Jingyi Wang \\ Changchun University Of Science and \\ Technology \\ 7089 Weixing Rd.Changchun \\ Jilin prov. China
}

\author{
Ruitao Li \\ Changchun University Of Science and \\ Technology \\ 7089 Weixing Rd.Changchun, \\ Jilin prov. China
}

\author{
Liyan He \\ Changchun University Of Science and \\ Technology \\ 7089 Weixing Rd.Changchun, \\ Jilin prov. China
}

\begin{abstract}
The LED node temperature rises with the increasing of power and it leads to sharp attenuation LED's life, according to these characteristics, combining active and passive cooling methods to design a new type of heat sink. The maximum temperature of LED is controlled in $43^{\circ} \mathrm{C}$. At last a heat analysis is done by ICEPAK.
\end{abstract}

\section{Key words- LED; Heat sink.}

\section{INTRODUCTION}

LED (Light Emitting Diode) is a kind of solid light sources to turn the electric energy to light . It may be lead to the fourth revolution of lighting industry with a new solid lamp to replace the incandescent and fluorescent lamp. Luminous efficiency especially the lowness of light extraction efficiency and the incapacity of heating are the main technical bottleneck of the lighting high power LED (power greater than $1 \mathrm{w}$ ).At present, the LED luminous efficiency can only be $10 \%-20 \%$, and $80 \%-90 \%$ of the energy conversion convert into heat, in order to ensure the service life of components, general requires the node temperature blows less then $110^{\circ} \mathrm{C}$.At present ,the size of the LED chips which meets the lighting high power is mostly in $1 \mathrm{~mm} \times 1 \mathrm{~mm}$ above, and once the heat flux density is beyond $100 \mathrm{~W} / \mathrm{cm}^{2}$, the heat will not transfer out timely, the heat gathered will cause the node temperature of LED increasing. And the node temperature directly affects the device from the efficiency of light, peak, wavelength, device life and so on. Therefore, solving the heat of LED becomes the primary problem of the high power LED lighting development.

TABLE 1 MAIN PASSIVE COOLING PATTERN CONTRAST

\begin{tabular}{|c|c|c|c|c|}
\hline Cooling way & Design complexity & Cost & $\begin{array}{c}\text { Extra power } \\
\text { consumption }\end{array}$ & Cooling effect \\
\hline active & high & higher & high & higher \\
\hline passive & low & lower & none & low \\
\hline
\end{tabular}

According to the table1, there are many problems in the existing LED cooling ways, they can't cool the device well. In view of the above problems, the present invention uses the method of combining active and passive cooling heat way, to make the temperature of LED drop substantially, so as to improve LED luminous rate and prolong the service life of LED.

\section{BASIC MECHANISM DESIGN}

LED lamps and lanterns thermal analysis formula:

$$
T_{j \max } \geq T_{a}+\left(R_{\text {thb-a }} \times P_{\text {total }}\right)+\left(R_{\text {thj-ap }} \times P_{\text {led }}\right)
$$

In the type:

$T_{j \max } \longrightarrow$ The theoretical node temperature of LED, Unit: ${ }^{\circ} \mathrm{C}$

$T_{a} \_$The temperature of using environment, Unit: ${ }^{\circ} \mathrm{C}$

$R_{t h b-a}$ Lamps and lanterns cooling unit total thermal resistance, Unit: ${ }^{\circ} \mathrm{C}$

$P_{\text {total }}$ LED's total power, Unit: W

$$
\begin{aligned}
& P_{\text {led }} \text { Single LED's power, Unit: W } \\
& R_{t h j-a p} \longrightarrow \text { Single LED's heat resistance,Unit: }{ }^{\circ} \mathrm{C} / \mathrm{W} \text {; }
\end{aligned}
$$

The highest temperature of design LED base plate environment is less then $45^{\circ}$, and select a single LED thermal resistance of $3{ }^{\circ} \mathrm{C} / \mathrm{W}$, according to the LED lamps and lanterns thermal analysis formula, only the method of reducing cooling unit thermal resistance can achieve the effect of heat dispelling.

Design USES seven star LED (3 w, LZ4 - c) were calculated

$$
\begin{aligned}
& T_{j \max }=120^{\circ} \mathrm{C} \\
& T_{a}=45^{\circ} \mathrm{C} \\
& P_{\text {led }}=0.1 \mathrm{~A} \times 21 \mathrm{~V}=2.1 \mathrm{~W} \\
& P_{\text {total }}=2.1 \mathrm{~W} \times 7=14.7 \mathrm{~W} \\
& R_{\text {thj-ap }}=3^{\circ} \mathrm{C} / \mathrm{W}
\end{aligned}
$$




$$
\begin{aligned}
& R_{\text {thb-a }} \leq\left(T_{j \max }-T_{a}-R_{\text {thj-ap }} \times P_{\text {led }}\right) / P_{\text {total }} \\
& R_{\text {thb-a }} \leq\left(120^{\circ} \mathrm{C}-45^{\circ} \mathrm{C}-3^{\circ} \mathrm{C} / \mathrm{W} \times 2.1 \mathrm{~W}\right) / 14.7 \mathrm{~W} \\
& R_{\text {thb-a }} \leq 4.67^{\circ} \mathrm{C} / \mathrm{W}
\end{aligned}
$$

From the above calculation we can get: when design of the cooling unit thermal resistance $R_{\text {thb-a }} \leq 4.67^{\circ} \mathrm{C} / \mathrm{W}$, the LED will work in the normal environment of $45^{\circ} \mathrm{C}$.

In order to achieve thermal design index, there are some specific design of cooling part as follow:

The design of air duct structure should use direct air duct as possible and try to avoid of flowing turning 、 sudden expansion or contraction ,then the inlet and outlet of wind should be set as far away as possible to prevent air short circuit. If there is not special requirements don't open vent on the cabinet, face plate, side panel board to preventing air short circuit. We design the whole air duct under the principles of air circulation and larger wind speed through hot area. Designing both side of panel be mutual correspondence and the front panel of the vent and internal fan blowing position corresponding to ensure through air duct, avoid air turning.

The design of encapsulate shell. The encapsulate shell is not radiator, so it use aluminum alloy material and the thickness is $2 \mathrm{~mm}$ considering of increasing cooling effect. From the point of thermal, encapsulation shell surface do not make any processing, because additional surface has no use of cooling, and increases the cost of product.

The installation of components. The installation of components should be as far as possible to reduce the thermal resistance between components surface, i.e., the contact thermal resistance. We use short path to minimize conduction heat resistance, i.e., as far as possible to avoid the thermal conductivity plate or cooling block the components of heat lead to the surface. The main task of PCB thermal design is effectively print circuit board heat guide to external. LED printed board thermal conductive glue to the guide cooling block base, reduce conduction heat resistance, and increase the contact area, heat faster conduction out.

The design of the radiator. In this design, radiator must be adopted to forced cooling way, so use the air-cooled heat dissipation. Due to the limitation of the structure size, so the design of guide and radiating is a guide cooling block, both positioning guide effect, and the effect of rapid heat dissipation .Concrete structure as shown,there is a circular groove on the guide cooling block base on using to set up the LED chip, the external cylinder of the groove is used for fit installation of the inner cylinder block of the guide cooling block briquetting. Aligne the guide cooling block base and guide cooling block briquetting vents .To ensure the air circulation, through the cooling block around four bolt hole connected with fixed ironing guide effect, and the effect of rapid heat dissipation. Projection lens has seven holes and seven LED lamps to cooperate, using lens thread compression ring to pressure lens, making its pressure in the LED lamp, lens thread compression ring outside thread and guide cooling block pressure of the inner cylinder block of inside thread fit. For ordinary air cooled radiator generally choose metal as radiator material, at the same time wish to has height heat and high heat conduction coefficient, the comprehensive consideration of two kinds of copper and aluminum materials all aspects of performance contrast: the thermal conductivity of copper is good, but the price is more expensive, and it difficult to processing, the density is larger, but copper radiator heating capacity is small and easy to oxidation. On the other hand , the pure aluminum is too soft to be directly used, but the use of aluminum alloy can provide enough hardness, aluminum alloy has the advantage of low price and light weight, just no good thermal conductivity of copper. So in this design USES the aluminum metal alloy material. The aluminum alloy of the heat conduction coefficient for 226 $\mathrm{w} / \mathrm{mK}$.

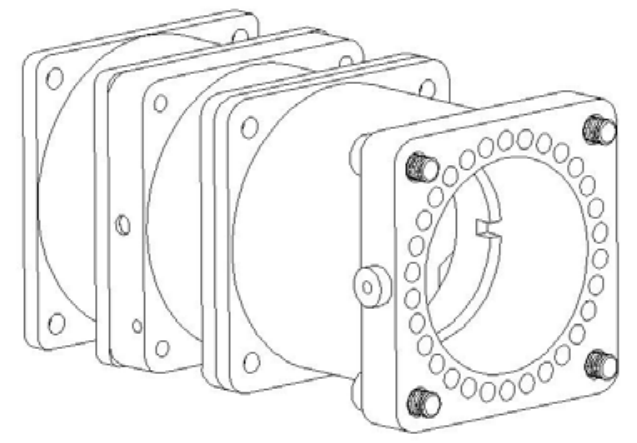

Figure 1 The structure of packaging hull

Fan design choices. For air cooled heat dissipation must through the fan of forced convection to speed up the quantity of heat to send out, and the stand or fall of fan for cooling effect also has played a decisive role. The choice of fan is mainly from the aspects of air volume, speed, noise, service life length and the type of fan blade bearing. The fan parameters of this design: imported double ball bearing, long service life up to 100000 hours; Large volume up to 27.55 CFM, have plenty of cooling air volume and air pressure; Size is $6.0 \times 6.0 \times 2.5 \mathrm{~cm}$; Speed for $5000 \mathrm{RPM}$ plus or minus $10 \%$; Noise is 40.0-10\%; Environmental temperature for - $10 \sim+70$ ${ }^{\circ} \mathrm{C}$; Voltage $24 \mathrm{v}$, the current $0.14+/-0.01 \mathrm{~A}$. The way of blowing may cool block. Fan installed in the system, the structural constraint, air inlet and outlet often can be affected by a variety of barrier and its performance curve can produce change, ensuring fan into diffuser best and stems $40 \mathrm{~mm}$ distance, with space limitation, at least $20 \mathrm{~mm}$.

\section{THE SIMULATION OF COOLING PART}

The machine designed is using Icepak thermal simulation software to analyse the heat transfer of whole structure and ventilated circumstance. The integral model simplified, set LED pyrogen maximum power $2.1 \mathrm{~W}$, set all kinds of material coefficient of thermal conductivity, fan characteristic curve, the environment temperature.

Through the icepak software simulation analysis we can get the whole structure of the wind speed distribution as figure 
2 shows, which represents the wind is blown ahead to back, and the fan set to blowing way, air volume in the LED printed board in cooling channel to achieve maximum wind speed, thus accelerate reduce LED base plate temperature.

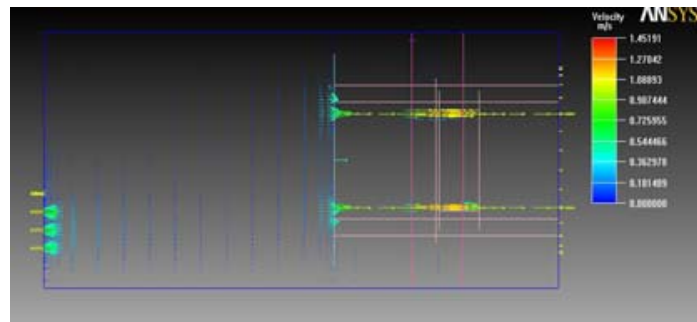

Figure 2 The wind speed distribution of the whole structure

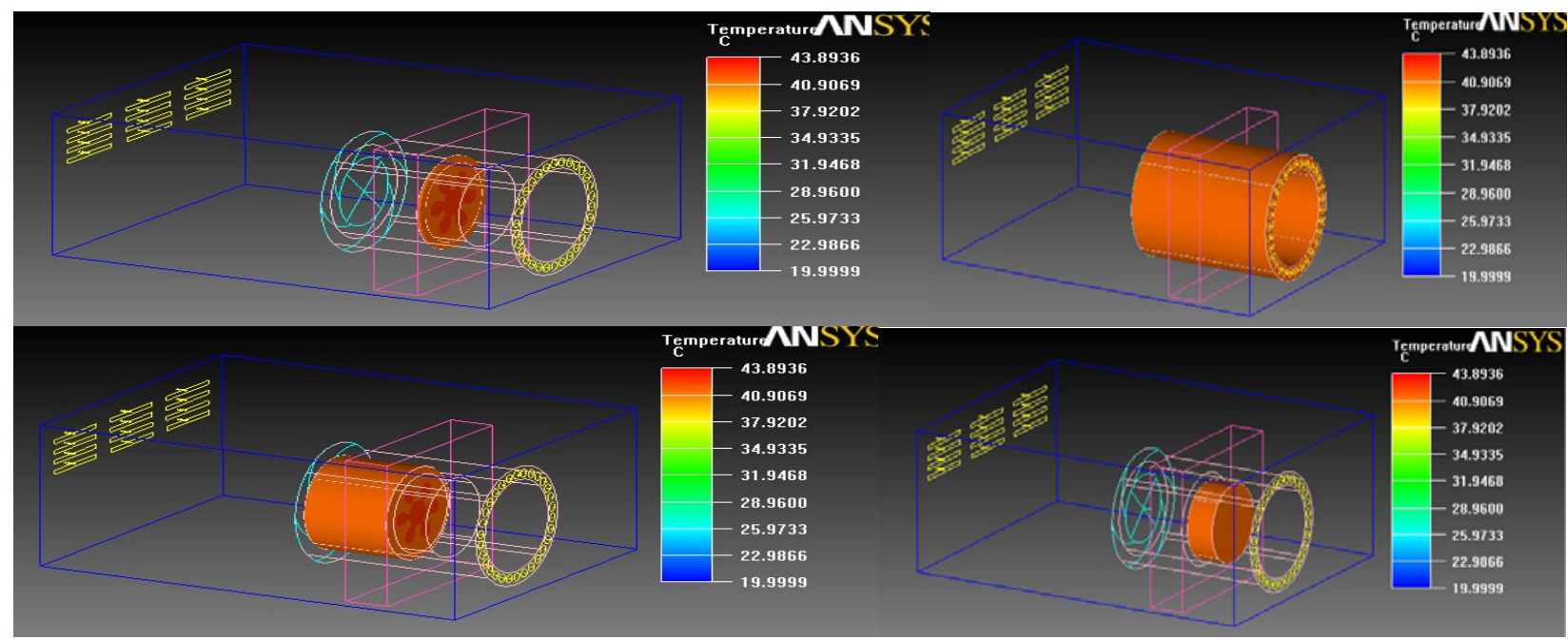

Figure 3 The temperature field distribution of model components

\section{CONCLUSION}

We can get the conclusion that the temperature is suitable for high power LED chip to work long hours, and then using the passive cooling combination of cooling way is a very good solution to solve the problem of high power LED heat dissipation than existing cooling way. No matter in the cost or the complexity of the design, it has more advantages..
Simulate model analysis of steady temperature field distribution as shown in figure 3 , from the graph we can see, the LED chip heat generation through the following solder and gap transfer to guide cooling base, because the base is aluminum materials, and thermal conductivity is much higher than the lens, so the most of the heat through the guide cooling block conduction, only a few part of heat transter to the lens. The highest temperature is at the graphic LED chip center, and the overall structure of the cooling performance is good, the LED chip to guide cooling base of thermal resistance is about $R_{t h b-a}=3.92^{\circ} \mathrm{C} / \mathrm{W}$, meeting the design requirements, and the similar structure compared with thermal resistance is low. 